\title{
МАТРИЧНАЯ МОДЕЛЬ УПРАВЛЕНИЯ БИЗНЕС-ПРОЦЕССАМИ ОРГАНИЗАЦИИ НА ПРИМЕРЕ ПИЩЕВОЙ ПРОМЫШЛЕННОСТИ
}

\author{
О.Н. РОДЦЕВИЧ \\ аспирантка кафедры экономики и управления \\ Белорусского государственного экономического университета, г. Минск
}

\section{Аннотация}

В статье рассматривается промышленнаяорганизация как элемент макросреды, взаимодействуюший с рынками покупателей и поставщиков. Акцентируется внимание на изменение управленческих технологий, которые должны быть напрвлены на повышение уровня конкурентоспособности предприятия. Универсального алгоритма для создания системы эффективного управления промышленными организациями не существует, однако возможна разработка общих принципов построения подобных систем управления бизнесом. К числу наиболее передовых методов построения систем эффективного управления можно отнести процессный подход.

В рамках процессного подхода к управлению организацией, в статье предлагаетсяпостроение матричной модели для совершенствования управления бизнес-процессами на примере предприятий пищевой промышленности. Особенностью модели является то, что сформированная матрииа дает возможность определить задачи уровня организационного подразделения (отдела), которые затем могут группироваться как по функциональному (по предмету деятельности) или процессному (по результату) принцииам, так и по рыночному событию.

Abstract

The article deals with industrial organization as part of the macro environment, interaction with the market buyers and suppliers. Attention is drawn to the change management techniques that must point to increase the competitiveness of enterprises. Universal algorithm to create a system of effective management of industrial organizations do not exist, however, possible to develop general principles of such systems of business management. The most advanced techniques of building effective management systems include the process approach. As part of the process approach to management of the organization, the article proposes the construction of a matrix model to improve the management of business processes on the example of the food industry. A feature of the model is that the generated matrix enables us to determine the level of the problem of the organizational unit (department), which can then be grouped both functional (on the subject of business) or process (the result) principles and on market developments.

\section{ВВЕДЕНИЕ}

Преобразования экономики Республики Беларусь привели к формированию новых экономических отношений субъектов хозяйствования с внешним окружением. Взаимодействие организаций с внешней средой требует выработки адаптивного поведения в конкурентной среде, что является условием устойчивого развития. Спад объемов производства, обусловленный снижением платежеспособного спроса на товары и услуги, изменения вертикали управления отраслями народного хозяйства, дефицит или отсутствие долгосрочных инвестиций, невозможность быстрой адаптации к новым условиям хозяйствования и перестройки мышления управленческих кадров, неразвитость рыночной инфраструктуры являются реальными условиями функционирования промышленных предприятий.

В сложившихся условиях отечественные предприятия вынуждены функционировать и развиваться в принципиально новых экономических условиях. При этом в ближайшие годы им предстоит выйти на устойчивый режим функционирования в условиях конкуренции, что потребует формирования адаптивного поведения в динамично меняющейся внешней среде [1].

Процесс вхождения белорусской экономики в систему рыночных коммуникаций, работа в условиях конкуренции и в нестабильной внешней среде требуют от организаций переосмыслить стратегию поведения. В условиях конкурентных отношений требуется пересмотр применявшихся методологических представлений и методов решения технико-экономических проблем развития промышленных организаций с выбором эффективных организационных структур и оптимизации основного капитала.

Адаптивное поведение промышленных организаций формируется под воздействием неопределенности внешней среды и внутренних проблем, возникающих в связи с изменением взаимоотношений с внешним окружением.

В условиях адаптивного поведения повышение эффективности деятельности предприятия базируется на новых формах и методах хозяйствования. Переход на новые методы требует проведения реинжиниринга, что, в свою очередь, требует модернизации структуры управления.

Проблемы управления, повышения эффективности деятельности, а также применения современных инструментов управления менеджментом предприятий исследуются отечественными учеными: И.Л. Акуличем, В.Ф. Байневым, И.В. Балдиным, Н.П. Беляцким, О.А. Высоцким, А.С. Головачевым, А.П. Дуровичем, Н.И. Кабушкиным, Г.А. Короленком, М.В. Петровичем, С.А. Пелихом, Е.С. Русак, А.Н. Сенько. Построению систем процессного подхода и его внедрению в управление предприятием, разработке методик процессного управления посвящены труды В. В. Репина, В. Г. Елиферова, А. С. Козлова, Г.Е. Герасимовой, В. С. Егорова, О. В. Буч, В. Ф. Лелякова, Й. Беккера, Л. Вилкова, В. Таратухина, М. Куглера, М. Роземанна и др. 
Несмотря на имеющийся опыт в области управления, методологические и методические вопросы формирования и функционирования системы управления, применительно к современным условиям деятельности белорусских предприятий, остаются недостаточно изученными. Опыт их применения в управлении зарубежными компаниями, накопленный к текущему моменту, не может в полной мере применяться отечественными предприятиями без его адаптации к существующим условиям и специфике хозяйствования. Следовательно, актуальным направлением исследований является проблема формирования механизма управления предприятием на основе процессного подхода, адаптированного к национальным условиям хозяйствования.

Таким образом, несмотря на значительное число публикаций, существует необходимость в продолжении исследований по совершенствованию управления бизнес-процессами организации.

\section{РЕЗУЛЬТАТЫ И ИХ ОБСУЖДЕНИЕ}

Промышленная организация как элемент макросреды. Любое современное предприятие является сложной системой, его деятельность включает в себя исполнение многих взаимовлияющих функций и операций. Моделирование упрощает систему восприятия взаимодействия процессов, обеспечивает возможность принятия аргументированных решений по их модификации. Для выполнения большинства задач по совершенствованию деятельности организации важным этапом является моделирование бизнес-процессов. При совершенствовании управления основными бизнес-процессами предприятий, необходимо выполнить их оптимизацию за счет учета взаимосвязи реализуемых функций по управлению производством. Так как управление организацией, в общем виде, заключается в разработке целей деятельности, доведение данных целей до исполнения и контроле по их достижению, то управление бизнес-процессами организации можно представить в виде схемы 1.

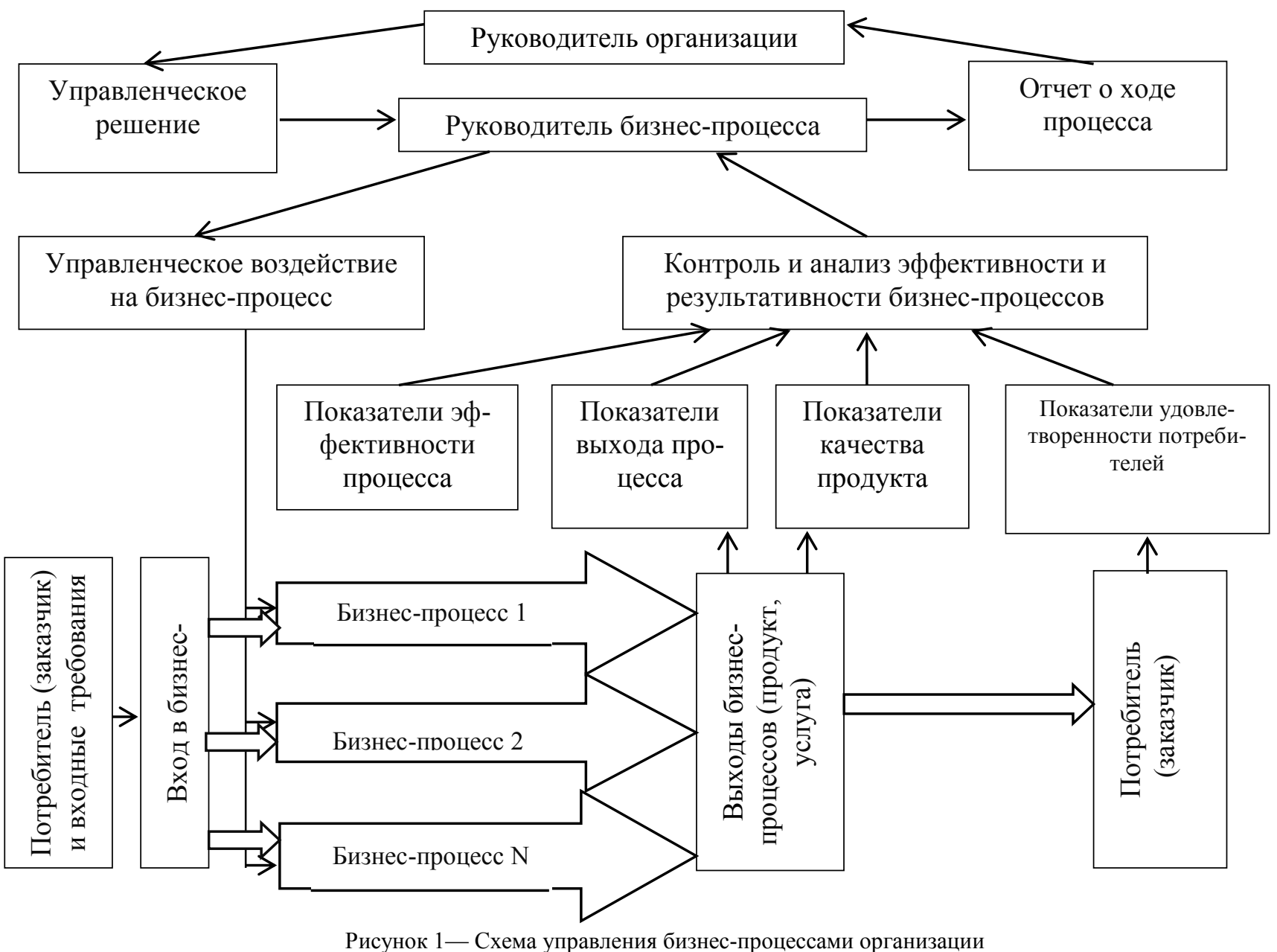

В представленной схеме управления бизнес-процессами выделяются два контура управления предприятием:

- первый контур: руководитель организации — руководитель бизнес-процесса;

- второй контур: руководитель бизнес-процесса - исполнители бизнес-процесса.

Выделение данных контуров позволяет распределить ответственность руководства организации за функционирование бизнес-процессов и достижение конечных целей деятельности.

Организация представляет собой элемент макросреды, взаимодействующий с двумя основными элементами макросреды - рынком покупателей и рынком поставщиков. Предприятие реагирует на спрос и потребность на рынке покупателей, и, в свою очередь, формирует спрос и потребность на рынке поставщиков, выступая для поставщика как 
элемент его уникального рынка покупателей. Ресурсы, полученные предприятием на рынке поставщиков, преобразуются (перерабатываются) предприятием в течение производственного процесса в продукт (товар или услугу), несущий в себе некую ценность, востребованную на рынке покупателей.

Для адекватной реакции на происходящие изменения на рынке покупателей и формирования стратегии поведения на рынке поставщиков, организации необходимо учитывать две основные системы:

- продуктовая (производственная система), реагирующая на изменения на рынке потребителей;

- ресурсная система, обеспечивающая продуктовую необходимыми ресурсами и вызывающая трансформацию на рынке поставщиков.

Ресурсная и производственная системы нормально развивающегося предприятия находятся в равновесном состоянии, одновременно и поддерживая, и ограничивая друг друга. Все бизнес-процессы организации функционируют в данных системах, обязательно имея на своей границе (начало, конец или и то и другое) взаимоотношения с макросредой.

Для того чтобы довести функции выделяемых бизнес-процессов организации до конкретного исполнителя, предлагается использовать матричную модель системы управления бизнес-процессами, в которой каждый из бизнеспроцессов может быть прописан с максимальной глубиной в соответствии с правилом, выдвинутым М. Хаммером и Д. Чампи: «Одна функция (работа) - один человек (должностное лицо)»[2].

Матричная модель. Организационная модель - это принципы формирования подразделений, делегирования полномочий и наделения ответственностью. На практике применяют следующие модели структурирования деятельности организации:

- функциональная модель: «одно подразделение = одна функция»;

- процессная модель: «одно подразделение = один процесс»;

- матричная модель: «один процесс или один проект = группа сотрудников из разных функциональных подразделений»;

- модель, ориентированная на контрагента: «одно подразделение = один контрагент (клиент или клиентская группа, поставщик, подрядчик и пр.).

Последняя модель применяется в случае, если рынок контрагента ограниченный. Например, в случае если число потребителей сильно ограничено, целесообразно применить модель, ориентированную на клиента или клиентскую группу: «одно подразделение = один клиент».

В большинстве же случаев распространение получили функциональная и процессная модели, а также их различные модификации.

Процессная структура наряду с достоинствами функциональной структуры имеет целый ряд преимуществ там, где функциональная структура имеет явные недостатки.

Матричные оргструктуры совмещают принципы построения функциональных и процессных систем. В этих структурах существуют жестко регламентированные процессы, находящиеся под управлением менеджера процесса. При этом деятельность осуществляется работниками, находящимися в оперативном подчинении менеджера процесса и в административном подчинении руководителя, находящегося в функциональном «колодце» [3].

По существу, роль менеджера процесса состоит в координации действий внутри процесса. Подобное решение, с одной стороны, не полностью реализует преимущества процессного подхода, а с другой стороны, не полностью устраняет недостатки функциональной системы. На практике матричные структуры хорошо применимы для организации управления проектной деятельностью, и мало подходят для регулярного менеджмента, так как содержат в своей природе некоторое двоевластие - процессов и функций.

Матричное управление - это гибрид децентрализации и централизации. Матричная организация устроена таким образом, что каждое отделение имеет как минимум двух руководителей. Вместо линейных цепочек подчиненности матрица обладает многомерностью - в зависимости от того, сколько измерений считается необходимым для пользы дела и является практически возможным.

Если применять различные модели организации деятельности в пределах отдельных бизнес-процессов, то можно использовать преимущества той или иной организационной модели. При этом для организации в целом будет применяться процессная организация основных структурных блоков, а в рамках отдельных блоков могут применяться различные модели. Например, для организации структурного блока, реализующего бизнес-процесс разработки новых и совершенствования существующих продуктов, целесообразно использовать матричную структуру; при определенных условиях для организации процессов воспроизводства ресурсов (зависимость от монополистов-поставщиков), воспроизводства средств производства (использование подрядчиков для выполнения работ), продвижения и продаж (работа с ограниченными клиентскими группами) целесообразно использовать модели, ориентированные на контрагента; структура финансовых служб будет выглядеть привычнее при функциональной организации.

Построение организационной структуры управления является одним из шагов проектирования системы управления организацией. Такие действия представляют из себя набор процедур, возможный для описания в формате IDEF 0 или IDEF 3, что позволяет описать каждую из них в программных продуктах типа Aris или Bpwin [4].

Бизнес-процессы в рамках матричной модели формируются исходя из стадий жизненного цикла продукта (либо ресурса) на предприятии. Стадии жизненного цикла продукта отображаются Z-диаграммой, показывающей взаимодействие стадий жизненного цикла продукта с макросредой.

Основных стадий жизненного цикла продукта в предлагаемой модели насчитывается семь: определение, развитие и разработка, прогнозирование, создание, заказ, отгрузка, обслуживание.

Указанные семь основных стадий жизненного цикла формируют семь основных сквозных процессов, происте- 
кающих на предприятии.

Выбор тех или иных субмоделей зависит от специфики и особенностей деятельности организации. Далее предпринята попытка сформировать матричную модель управления бизнес-процессами организации пищевой промышленности.

Отметим, что наибольшей актуальностью для привлечения инвестиций обладают те отрасли, потенциал развития которых способен качественно изменить экономическую ситуацию в стране. К одной из таких отраслей относится пищевая промышленность, предприятия которой обеспечивают текущие естественные потребности населения. Пищевая промышленность является одной из базовых отраслей, поэтому каждая страна уделяет первостепенное значение ее экономическому состоянию[5].

Роль пищевой промышленности в развитии национальной экономики Республики Беларусь определяется прежде всего тем, что она обеспечивает рациональное питание населения, способствует устранению неравномерности потребления пищевых продуктов как во времени, так и в региональном разрезе, позволяет эффективно использовать сельскохозяйственное сырье, сокращать его потери [6].

Белорусский государственный концерн пищевой промышленности «Белгоспищепром» является основным производителем пищевой продукции в стране и проводит единую экономическую, техническую и технологическую политику в пищевой промышленности Республики Беларусь, которая включает более 20 подотраслей, производящих сотни наименований продовольственных товаров. В состав концерна входит 57 организаций. [7]

Необходимо отметить, что производство пищевых продуктов (включая напитки) и табака занимает наибольший удельный вес в структуре обрабатывающей промышленности Республики Беларусь занимает 26,6 \%,a в общем объеме промышленного производства - 23,6 \% [8]. В 2014 году в пищевой промышленности функционировало свыше 800 организаций. В отрасли занято более 150 тыс. человек, что составляет 14,5 \% от числа работающих в промышленном секторе.

Пищевая промышленность Республики Беларусь, несмотря на негативные изменения рынка, развивается достаточно успешно. Так, в 2014 г. по сравнению 2013 г., наблюдается положительная тенденция к росту по объему произведенной продукции на 23995217 млн. руб. В первом полугодии 2015 г. объем производства организаций пищевой промышленности составил 82 673,1 млрд. руб., а индекс производства составил в сопоставимых ценах 99,2 \% к уровню первого полугодия 2014 г.

По данным Национального статистического комитета, в январе-феврале 2015 г. выручка предприятий пищевой промышленности от реализации продукции, товаров, работ и услуг составила 22 351,9 млрд. руб., что на 5,2\% больше, чем за аналогичный период 2014 г. При этом прибыль предприятий отрасли от текущей деятельности за два месяца 2015 г. оказалась равна 1 699,5 млрд. руб. или на 1,2\% больше, чем за январь-февраль 2014 г.

На предприятиях пищевой промышленности выполняется большое количество различных процессов, что создает определенные трудности при их выделении и описании. Пищевая продукция обладает особой востребованностью на потребительском рынке, т.к. удовлетворяет в первую очередь физиологические потребности человека. Именно к ней предъявляются самые жесткие требования по безопасности и другим показателям, составляющим качество потребляемых человеком продуктов питания. В то же время, пищевые продукты часто имеют очень короткий жизненный цикл, т.к. многие потребители переходят на совершенно новые продукты (низкокалорийные, обладающие диетическими свойствами, отличительными вкусовыми качествами и т.д.). Качество пищевых продуктов сегодня определяется не только объективно измеряемыми показателями (содержание жира, белков, углеводов, витаминов, влаги и т.д.), но и их способностью удовлетворять индивидуальные потребности потребителей. Предприятия пищевой промышленности должны создавать единую систему менеджмента, направленную на повышение эффективности управления производством и качества выпускаемой продукции в соответствии с требованиями рынка.

Описание бизнес-процессов предприятий пищевой промышленности при помощи разработки различных моделей обеспечивает прозрачность, которая необходима для проведения изменений их деятельности без потери контроля над бизнесом.

На основе матричной модели организации предложенной Д. Хлебниковым, А. Яцына и Л. Савушкиным [9], сформирована матричная модель системы управления бизнес-процессами организации пищевой промышленности Республики Беларусь.

Пересечение подсистем и процессов определяет задачи, возлагаемые на отдельные подразделения (рисунок 3 ). Иерархия, последовательность решения задач, их приоритетность и направления информационных потоков отражается на модели стрелками.

Матричная модель позволяет применять три основных типа формирования организационной структуры (процессный, функциональный или матричный) практически одновременно, в зависимости от особенностей организации производственного процесса и стратегий развития предприятия.

Формирование и определение деятельности на уровне отделов происходит путем наложения стратегических целей предприятия и объемов затрат на выпуск продукции на полученную матрицу задач, в рамках чего придаются приоритеты тем или иным направлениям деятельности, компетенциям и результатам работы.

В рамках моделирования предприятия производится приведение в соответствие целей предприятия в целом и отдельных его подразделений. Система управления подразделением предусматривает формирование системы обратных связей, благодаря которым происходит корректировка процессов планирования последовательностей результатов, определения рабочих процедур и определения ресурсов. Блок процесса «Производство» представляет собой выполнение процедур и затраты материальных средств, выделенных на эти процедуры. Практически процессы управления процедурами являются работами по планированию последовательностей шагов достижения поставленной задачи, 
каждый из которых может, в свою очередь, быть разложен на составляющие действия.

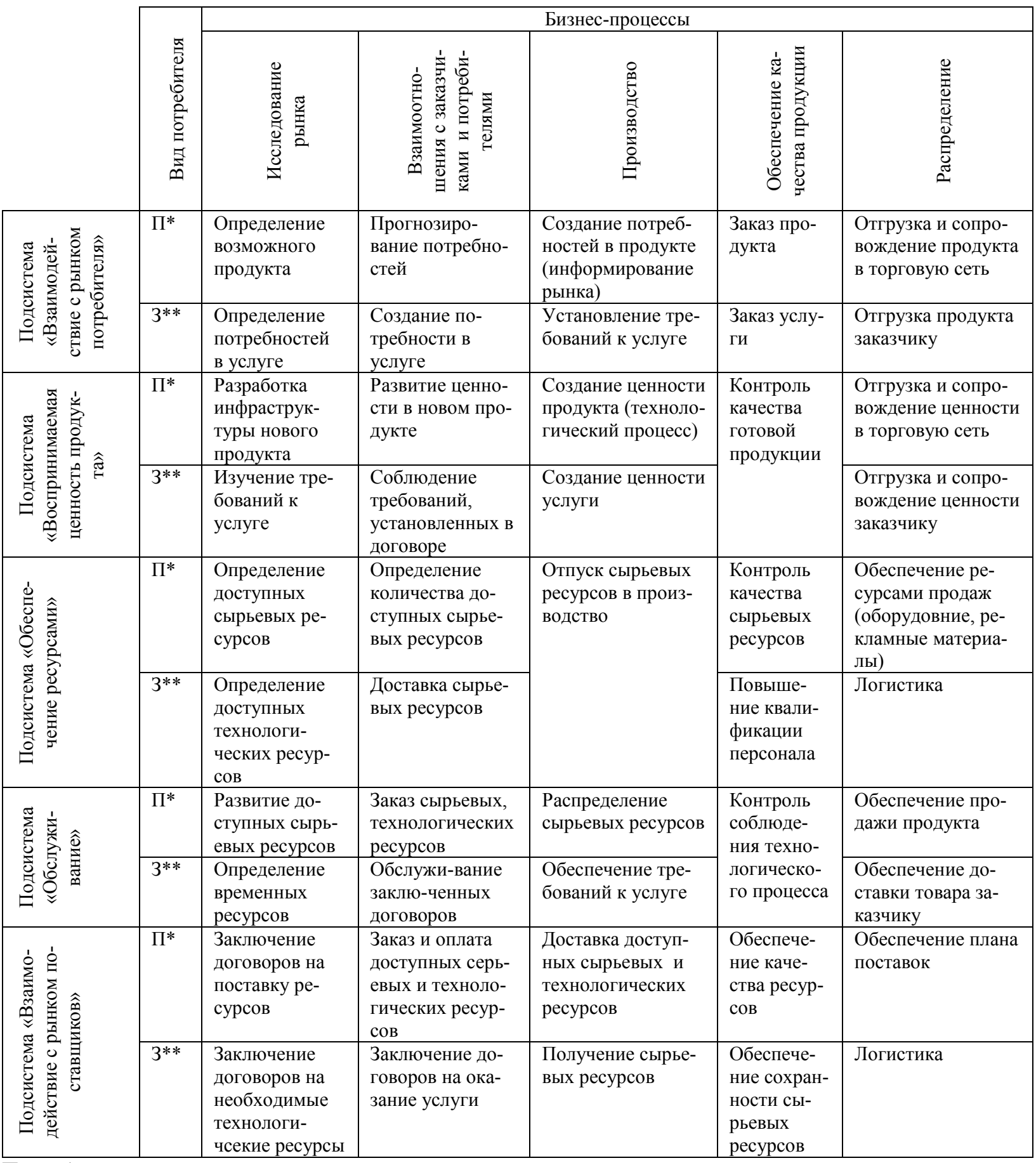

П*-- Потребитель

3**-- Заказчик (организация)

Рисунок 2 - Матричная модель системы управления бизнес-процессами организации пищевой промышленности Республики Беларусь.

Соответственно, при распределении целей между производственными подразделениями в зависимости от стратегии развития предприятия для каждого из подразделений выстраивается свой набор шагов, каждый из которых представляет собой некоторую последовательность действий. 


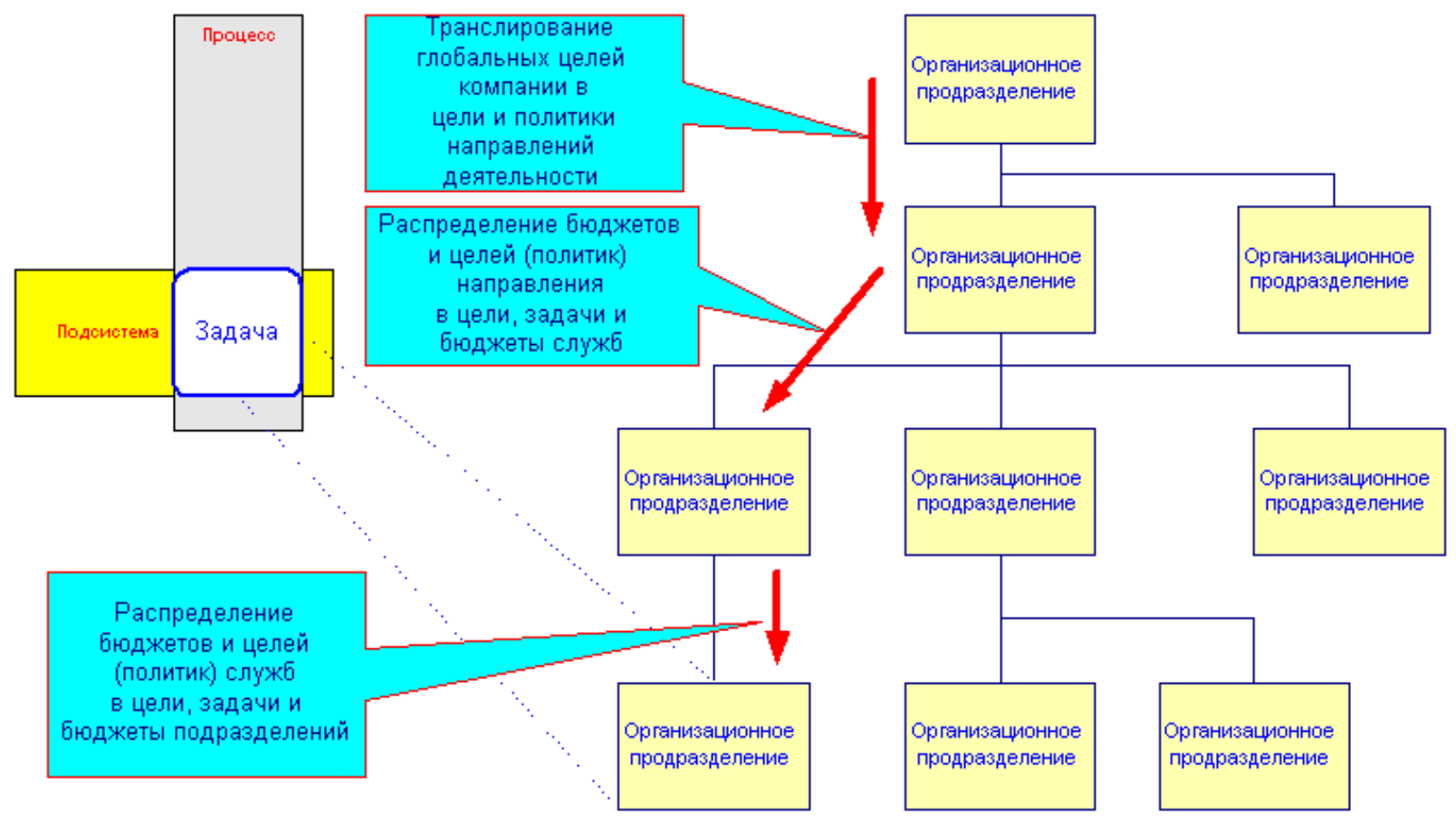

Рисунок 3- Формирование задачи для подразделения организации [10].

\section{ВЫВОДЫ}

В результате проведенного исследования установлено, что на эффективное управление предприятием пищевой промышленности существенное влияние оказывают отраслевые особенности: размер предприятия (в основном это предприятия малого и среднего бизнеса); отсутствие формализованной стратегии и долгосрочного планирования; продажа продукции в строго ограниченном географическом районе; сезонность производства; отсутствие внимания к мотивации персонала; недостатки в организационной структуре (замкнутость структурных подразделений на первых руководителей, рассредоточенность и дублирование функций и др.); макроэкономические факторы и др.

Процессный подход к управлению предприятиями пищевой промышленности обладает высоким организационным потенциалом. Внедрение процессного подхода обеспечивает предприятию ряд возможностей и преимуществ: позволяет доводить корпоративные цели до каждого исполнителя работ, взаимно увязывать и согласовывать все процессы предприятия; обосновывать и выделять необходимые ресурсы; реализовывать новое качество управления, основанное на прозрачности механизма функционирования и управления процессами. Процессный подход к управлению предприятием выстраивает процесс управления в единую логическую цепь. Данную цепь можно представить в виде матричной модели управления бизнес-процессами организации.

Особенностью матричной модели является то, что сформированная матрица для предприятия, определяет задачи уровня организационного подразделения (отдела), которые могут затем группироваться как по функциональному (по предмету деятельности), так по рыночному событию или по процессному (по результату) принципам. Таким образом, матричная модель позволяет применять три основных типа формирования организационной структуры практически одновременно - в зависимости от особенностей бизнеса и стратегий развития компании.

В модели учитываются как особенности жизненного цикла продукта, особенности жизненного цикла ресурсов, вопросы бюджетирования и планирования работ. Вопросы администрирования решаются путем композиции подразделений по процессному, функциональному или матричному принципу. Вопросы персонала могут рассматриваться с ресурсной точки зрения, т.е. компетенции - как ресурсы, используемые бизнес-системой [11].

Матричная модель позволяет моделировать деятельность практически любого предприятия. Особенностью подхода является возможность как объединять задачи (по процессам и по системам), так и оставлять «белые» пятна. Модель имеет одну важную особенность при ее рассмотрении - она показывает, каким образом происходит агрегирование работ при составлении модели верхнего уровня. Ценность такого агрегирования состоит в возможности переименования задачи под конкретные условия и особенности деятельности предприятия, т.е. «локализации» модели.

Одним из достоинств представленной модели является возможность ее использования как менеджерами по управления (синтез бизнеса), так и разработчиками программных средств для автоматизации деятельности организации, так как в модели существует логичный и последовательный переход от модели верхнего уровня к конкретным операциям. 


\section{ЛИТЕРАТУРА}

1. Репин, В.В. Процессный подход к управлению. Моделирование бизнес-процессов / Репин В.В., В.Г. Елиферов. - 2-е издание - М.: «Стандарты и качество», 2005. - 408 с. - С. 48.

2. Хаммер, М. Реинжиниринг корпорации. Манифест революции в бизнесе / М. Хаммер, Д. Чампи. - М.: Манн, Иванов и Фербер, 2011. - 288 с. - С. 48.

3. Мескон, М. Х. Основы менеджмента: Пер. с англ. / М.Х. Мескон, М. Альберт, Ф. Хедоури - М.: «Дело ЛТД», 1995. - 704 с. - С. 71.

4. Железко, Б.А. Реинжиниринг бизнес-процессов: учеб. пособие / Б. А. Железко, Т. А. Ермакова, Л. П. Володько; под общ. ред. Б. А. Железко. — Минск: Книжный Дом; Мисанта, 2006. — 216 с. - С. 90.

5.Модернизация белорусской экономики: фундаментальные и прикладные аспекты: монография / С.Ю. Солодовников [и др.]; под ред. Ю.В. Чеплянского.- Минск: Экоперспектива, 2013. — 324 с. - С. 278.

6. Назаренко, В. В. Акцент на инновации и конкурентоспособность / В. В. Назаренко // Стандартизация. 2013.— № 3. - С. 9-14. - С. 13 .

7. Концепция Государственной программы инновационного развития Республики Беларусь на 2011-2015 годы. - Минск: Амалфея, 2010. — 228 с.

8. Беларусь в цифрах. Статистичекий справочник, 2015. - Минск: Нац. стат. ком. Респ. Беларусь, 2015.— 75 с.

9. Хлебников, Д. Матричная модель предприятия. [Электронный ресурс]/ Бизнес Инжиниринг Групп - Режим доступа: http://bigc.ru/publications/other/restruct/matrix_model_company.php — Дата доступа: 06.07.2015.

10. Хлебников, Д. Матричная модель предприятия. [Электронный ресурс]/ Бизнес Инжиниринг Групп - Режим доступа: http://bigc.ru/publications/other/restruct/matrix_model_company.php — Дата доступа: 06.07.2015.

11. Родцевич, О.Н. Современные подходы к управлению организацией / О.Н. Родцевич // Вестник Полоцкого государственного университета. Серия D. Экономические и юридические науки. — 2013. — № 13 - C. 67-74. - C.68.

Статья поступила в редакичию 4 июля 2015 года 